\title{
A NOTE ON TABLES, REFERENCES, AND RUBLE VALUES
}

Text tables are numbered consecutively. Appendix tables carry the letter designation of the appendix plus an arabic numeral-for example, K-1-and are located at the end of their respective appendixes. In all tables, the symbol "-" means zero or insignificant; the symbol ". ." means not available; the symbol "n.a." means not applicable. Differences between totals and sums of components are due to rounding unless otherwise indicated.

For brevity, references in text footnotes, table sources, and the appendixes supply only the author's last name and omit titles of articles: for example, Karcz, American Economic Review, June 1964. When reference is to an article other than in a journal, the author's name will be followed by the word "in" and the title of the work: for example, Karcz, in New Directions in the Soviet Economy, 1966. Complete references will be found in the bibliography under the author's name. Explanation of the abbreviations of references used in the footnotes, tables, and appendixes is provided in a list of short titles preceding the Bibliography.

Unless otherwise specified, all values in this book are expressed in "new" domestic rubles, in force from 1961. One "new" ruble equals ten (pre-1961) "old" rubles. The foreign trade ruble at which Soviet imports and exports are valued externally has no necessary relation to the domestic ruble. One "new" foreign trade ruble equals 4.4 (pre-1961) "old" foreign trade rubles. 
